\title{
Pena, salvação e direitos humanos na APAC: uma breve análise teológica e antropológico-jurídica da Associação de Proteção e Assistência aos Condenados
}

\author{
Penalty, salvation and human rights at APAC: \\ A brief theological and anthropological-legal analysis \\ of the Association for the Protection and Assistance of \\ the Condemned
}

José do Nascimento Lira Júnior

\section{Resumo}

"Matar o criminoso e salvar o homem" é o controverso slogan de uma instituição prisional alternativa conhecida como Associação de Proteção e Assistência aos Condenados. Para uma melhor compreensão desta ideia, "matar para salvar", é necessária uma maior aproximação empírica da proposta apaqueana, analisando o seu método de reclusão com as funções da pena nela exercidas, bem como os conceitos de salvação cristã que lhe são inerentes. Neste trabalho, pelo método bibliográfico - lançando mão de referenciais como: a filosofia apaqueana de Mário Ottoboni, passando, superficialmente, pela cristologia Jürgen Moltmann e Alfonso Garcia Rubio, até aos artigos $5^{\circ}$ a $11^{\circ}$ da Declaração Universal dos Direitos Humanos -, será possível notar essas características para, a partir delas, tentar dar resposta(s) ao problema: qual é a relação entre teologia e direitos humanos na APAC? Este é o propósito deste artigo, a saber, mais especificamente: observar a relação existente entre a proposta salvífica da APAC e o exercício dos direitos humanos em suas unidades. 
Palavras-chave: Teologia. Direitos Humanos. APAC.

\begin{abstract}
"Killing the criminal and saving the man" is the controversial slogan of an alternative prison institution known as the Association for the Protection and Assistance of the Condemned (APAC). For a better understanding of this idea, "killing to save", a greater empirical approximation of the APAC proposal is necessary, analyzing its method of seclusion with the functions of the sentence exercised therein, as well as the concepts of Christian salvation that are inherent to it. In this work, through the bibliographical method - using references such as: the philosophy of Mário Ottoboni, passing, superficially, through the Christology of Jürgen Moltmann and Alfonso Garcia Rubio, to articles 5 to 11 of the Universal Declaration of Human Rights - will be it is possible to note these characteristics to try to find the answer(s) to the problem: what is the relation between theology and human rights in APAC? This is the purpose of this article, namely, to observe the relationship between APAC's salvific proposal and the exercise of human rights in its units.
\end{abstract}

Keywords: Theology. Human Rights. APAC.

\title{
Introdução
}

Este texto, apesar de inédito, se baseia especialmente na experiência de 14 anos de pesquisa sobre a Associação de Proteção e Assistência aos Condenados - experiência esta registrada na defesa de dissertação de mestrado, na tese de doutorado, além de artigos publicados. ${ }^{1}$ Neste tempo percebeu-se que, com $721.461^{2}$ pessoas privadas de liberdade, o Brasil, em 2015, ocupou a terceira posição na lista dos países com a maior população carcerária do mundo. Atualmente, mais precisamente em 10 de agosto de 2020, o Brasil se mantém neste ranking, com cerca de 882.080 condenados. A cada dia, cerca de

\footnotetext{
${ }^{1}$ No decorrer do artigo, bem como na referência bibliográfica, alguns destes trabalhos serão citados.

${ }^{2}$ Em 11 anos esse número mais quase triplicou, pois, em 2009, era de 321.014 detentos, segundo o IPEA - Instituto de Pesquisa Econômica Aplicada, Reincidência Criminal no Brasil: Relatório de Pesquisa, 2015.
} 
281 indivíduos são presos em nossa país. ${ }^{3}$ Nesse ritmo, em aproximadamente 10 anos, o Brasil poderá ocupar a $2^{\mathrm{a}}$ colocação nesse lamentável ranking. As consequências desta estatística, dentro da atual estrutura do sistema prisional, são um enorme desafio para o governo, para a sociedade e para os pesquisadores. Quanto mais se propagam as rebeliões nos presídios brasileiros mais se evidenciam as fragilidades do seu sistema penitenciário que alguns consideram falido. ${ }^{4}$ Dentre estas fragilidades podem ser destacadas algumas das mais divulgadas pela mídia: superlotação, corrupção, tráfico de drogas, tráfico de influências, assassinatos, crime organizado, disputas de facções criminosas, etc. Aliado a tudo isso, e como consequência, os direitos humanos dos envolvidos direta ou indiretamente no sistema prisional são violados. Os encarcerados, os carcereiros, os familiares de ambos, todos sofrem, em maior ou menor grau, as consequências da falência de um sistema que apenas pune e piora as coisas, ao invés de reeducar para melhorar.

Neste contexto prisional brasileiro, há quase 50 anos, faz-se presente a filosofia penal apaqueana. Esta foi gerada a partir de 1969, no seio do Movimento Cursilhos da Cristandade (MCC), ${ }^{5}$ na Cidade de São José dos Campos-SP, onde se desenvolveu e, com o incentivo da Pastoral Penitenciária, se estabeleceu como instituição prisional a partir de $1974 .{ }^{6}$ Com ideais e práticas cristãs, a APAC tem procurado exercer a sua função penitenciária em cumprimento do Código Penal Brasileiro, ao mesmo tempo em que se esforça por resguardar, na prática, os direitos humanos dos reclusos. Direitos estes, garantidos internacional e nacionalmente. ${ }^{7}$

${ }^{3}$ BANCO Nacional de Monitoramento de Presos (BNMP 2.0). Em 17/01/2019, havia 721.461
detentos no Brasil. Em 18/01/2019, 722.685 presos. Em 20/01, 723.105. Em 27/01/2019,
728.697 . Em 19/08/2019 havia 817.685 presos no país. Finalmente, em 10 de agosto de 2020,
este número esteve em 882.080 presos no país. Constatou-se, neste período, um impressionante
aumento da população carcerária brasileira: cerca de 281 por dia. Como esta breve observação
foi realizada especificamente para este artigo, pretende-se dar continuidade afim de melhorar a
precisão dessa estatística.
${ }^{4}$ Dentre os teóricos mais destacados, neste caso, está BITENCOURT, C. R., Falência da pena
de prisão.
${ }^{5}$ OTTOBONI, M., O testemunho de minha vida e a vida de meus testemunhos.
${ }^{6}$ Em São José dos Campos também viveu e faleceu, em 14/01/2019, o fundador da APAC,
o advogado e jornalista, Mário Ottobonni. Para conhecer mais sobre a bibliografia de Mário
Ottobonni, o papel social da religião presente na instituição por ele fundada, bem como o
alcance desta instituição no Brasil e no mundo, convém consultar outras publicações do autor,
como: LIRA JUNIOR, J. N., Matar o criminoso e salvar o homem: o papel da religião na recu-
peração do penitenciário. 
Assim, o caminho a ser percorrido, nesta breve análise da relação teologia-direitos humanos, especialmente na APAC, obedecerá ao itinerário a seguir. Num primeiro momento, observar-se-á a questão jurídica penal na APAC, ou seja, como a referida instituição se encontra dentro das três funções da pena. Em seguida, será necessário analisar a sua proposta salvífica: como teologicamente ela enxerga a recuperação do condenado. Finalmente, verificarse-á em que medida os direitos humanos - especialmente os explícitos nos artigos $5^{\circ}$ a $11^{\circ}$ da Declaração Universal dos Direitos Humanos (DUDH) são garantidos dentro da proposta apaqueana. A hipótese é de que os direitos humanos aplicados nesta instituição sejam o resultado da relação dialógica entre a teologia e o direito penal que lhe são inerentes.

\section{As funções da pena na APAC}

No Brasil, é perceptível a coerência das finalidades da pena de prisão apenas no que tange à punição propriamente dita - uma consequência da dura realidade constatada na análise diacrônica da pena. ${ }^{8}$ Sincronicamente, a degradante realidade do sistema prisional brasileiro em relação às três funções básicas da pena - punir, prevenir e ressocializar - é observada em muitas pesquisas ${ }^{9}$ e, também, em efeitos sociais, tais como: o alto índice de reincidência criminal e os vandalismos. Destarte, ao contrário do que pensa a maioria do senso comum, ao tratar o indivíduo desviante impondo-lhe apenas o aspecto talião da pena, ao invés de se solucionar um problema, cria-se outro ainda maior. Há um efeito bumerangue sofrido pela sociedade, na medida em que esta paga caro para manter um condenado atrás das grades, num ambiente hostil e desumano, que irá devolvê-lo, via de regra, social e psicologicamente, pior do que era antes de entrar na prisão. O problema não está na punição em si - para a maioria dos juristas a pena é necessária. ${ }^{10} \mathrm{O}$ problema não está na

na teoria. Na prática a realidade é bem diferente. Uma observação participante, do sistema apaqueano, mostrará que, apesar de alguns aspectos sujeitos às críticas - como práticas religiosas muito disciplinadas, por exemplo -, não há como negar a existência de um cumprimento da pena que se esforça por respeitar à dignidade humana dos detentos.

${ }^{8}$ Para um olhar mais diacrônico da história penal, convém destacar: PINHO, R. R., História do Direito Penal Brasileiro; MOTTA, M. B., Crítica da Razão Punitiva; NEDER, G., Sentimentos e Ideias Jurídicas no Brasil, dentre outros.

${ }^{9}$ Dentre os muitos estudos, estão alguns dos mais recentes: PARENTE, F., Ressocialização; GRECO, R., Sistema Prisional; MARTINS, J. D., A condição do Encarcerado no Sistema Prisional. ${ }^{10}$ BITENCOURT, C. R., Falência da pena de prisão, p. 97-134. 
Lei de Execução Penal, na qual as funções da pena são perceptíveis, ${ }^{11}$ mas, via de regra, na prática da sua execução.

A característica do Centro de Reintegração Social, da Associação de Proteção e Assistência ao Condenado, é de estabelecimento penal. As peculiaridades da APAC, como a ausência de agentes policiais, ${ }^{12}$ não a descaracterizam como penitenciária. O CRS é, em suma, a estrutura física da APAC, dividida em pavilhões que abrigam condenados dos três regimes: fechado, semiaberto e aberto. Isto significa dizer que a APAC exercita, cumpre, a primeira das três funções da pena, a saber, a punitiva. O fato de se tratar de um sistema alternativo, com peculiaridades como as que serão rapidamente lembradas no decorrer desta reflexão, não elimina o caráter punitivo do cumprimento da pena nesta instituição. Definitivamente, falar do sistema apaqueano de reclusão é se referir a um sistema punitivo. Porém, na teoria, como na prática, a função da pena ali não se resume a este aspecto.

Ainda em coerência com o Art. 59 da Lei de Execução Penal, o sistema apaqueano visa à prevenção do crime. No sistema comum, espera-se que a punição sofrida pelos condenados sirva de exemplo e, com isso, haja prevenção. Entretanto, as estatísticas criminais demonstram que tal expectativa é utópica na medida em que tanto a criminalidade como a população carcerária crescem, diariamente, num ritmo frenético. Obviamente, não se espera a extinção do crime na Terra - isto, do ponto de vista das ciências humanas, como a teologia, a antropologia, a sociologia, etc., seria ainda mais utópico. Porém, espera-se, sim, a sua máxima repressão via melhores sistemas de saúde e de educação e, no caso penal, via sistema punitivo-preventivo-reeducador mais eficiente. A APAC, em quase meio século de sua existência, busca essa eficiência quando, pela alteridade peculiar ao seu método, tenta mostrar ao recuperando e à sociedade que o crime realmente não compensa. O sistema apaqueano, como veremos na parte final deste trabalho, tem os seus elementos básicos impregnados do aspecto exemplar da pena, bem como na prática nos direitos humanos ali. Além disso, são inúmeros os casos em que ex-recuperandos,

${ }^{11}$ É possível notar as funções da pena nos artigos do Código Penal de 1984, Lei n. ${ }^{\circ}$ 7.209, de 11 de julho de 1984, como o Art. 59 e o At. 91, por exemplo.

${ }^{12} \mathrm{O}$ segundo dos doze elementos que compõem o método apaqueano é "o recuperando ajudando o recuperando". Este elemento consiste não apenas na camaradagem de um recuperando para com o seu colega de cela, mas, especialmente em supervisioná-lo. Não há a necessidade de presença policial, nem de agentes penitenciário, porquanto as tarefas destinadas a estes - como abrir e fechar as celas para o banho de sol, abertura e fechamento do portão principal - são distribuídas entre os próprios recuperandos, observadas as devidas regras meritórias. 
ressocializados, voltam à APAC para contar aos atuais recuperandos o quanto foi válida a experiência de cumprimento da pena ali.

Todavia, a punição e a prevenção não são as únicas das três funções da pena encontradas na APAC. Em concordância com o Art. $1^{\circ}$ da Lei de Execução Penal, quando afirma ter a pena o objetivo de "efetivar as disposições de sentença ou decisão criminal e proporcionar condições para a harmônica integração social do condenado e do internado", o sistema apaqueano visa também a reeducar os que cumprem pena em suas unidades. Ali, esta função - que também é um dos direitos humanos, como será um pouco melhor analisado no terceiro ponto - se dá em parceria com a sociedade civil local e regional: comarcas, poderes legislativos e executivos, médicos, dentistas, empresários, familiares dos recuperandos, igrejas, etc. ${ }^{13}$ É importante lembrar que a ressocialização coroa a tríplice função da pena, bem como todo o trabalho do sistema penal, ao devolver à sociedade um indivíduo pronto para integrá-la de maneira saudável, ou seja, com o mínimo de reincidência. Nesta estatística a APAC também se destaca. Enquanto no sistema comum o índice de reincidência criminal gravitava em torno dos $70 \%$ ou $80 \%{ }^{14}$ em 2008 , no sistema apaqueano do Rio grande do Norte, por exemplo, esse índice é de $15 \% .^{15}$

\section{A proposta salvífica da APAC}

Analisado o aspecto jurídico penal, as funções da pena na APAC, faz-se necessária uma breve análise teológica, a saber, a proposta salvífica desta instituição, antes de se adentrar na questão dos direitos humanos ali. Também observarse-á, objetivamente, como a APAC relaciona, ideológica e administrativamente, os aspectos antropológicos jurídicos penais, analisados anteriormente, com os aspectos teológicos, destacados neste momento da pesquisa.

O conceito salvífico da APAC não é apenas teológico, mas, também socioantropológico, quando visa à ressocialização do apenado. Isso porque, o que no direito, e noutras ciências humanas, chama-se de recuperação, na teologia pode-se chamar de salvação - este, um tema igualmente complexo dados os diferentes enfoques dos contextos históricos nos quais se desenvolveu.

\footnotetext{
${ }^{13}$ Para uma melhor compreensão das funções da pena nos elementos do método apaqueano é importante consultar a seguinte referência: OTTOBONI, M., Vamos Matar o Criminoso?

${ }^{14}$ IPEA - Instituto de Pesquisa Econômica Aplicada, Reincidência Criminal no Brasil, p. 11.

15 APAC Tem Reincidência Quatro Vezes Menor que Regime Comum no RN. Conselho Nacional de Justiça - CNJ, 2017.
} 
Da problemática bíblica, passando pela histórica, à atual, falar de salvação cristã é falar também de dom, de resgate, de libertação, com todas as suas implicações. Por isso, ciente de que destacar a noção apaqueana de salvação cristã não é uma tarefa simples, este ponto limitar-se-á à breve análise dessa salvação como gratuidade e como libertação, porquanto há outros conceitos salvíficos (como o de resgate e o de satisfação vicária) que também se aplicam à APAC. ${ }^{16}$

Há muito o que se falar sobre a salvação como gratuidade, mas, como já foi dito, não é este o objetivo aqui. Porém, é fundamental lembrar que no cristianismo o ser humano foi criado, mantido e salvo pela graça. Esta salvação cristã se dá pelo deslocamento do Outro em direção ao agraciado, isso em atitude kenótica. Em Moltmann, tal atitude kenótica é trinitária e não apenas da Pessoa do Filho. ${ }^{17}$ Assim, trata-se de doação completa e voluntária, por parte do Salvador, e não de uma questão de mérito, por parte do salvo ou seja, trata-se de experiência exógena. Enquanto dom, expressão salvífica muito similar à gratuidade, é uma iniciativa do Salvador que vem ao encontro dos salvos em amor-serviço.

É importante salientar que tal gratuidade, como qualquer outro conceito de salvação cristã, não anula a necessidade de resposta por parte do beneficiado. A salvação de Jesus Cristo é oferta gratuita, mas é também resposta humana que pode ser enxergada, por exemplo, na prática querigmática, bem como na conversão e na fé, como lembra Alfonso Garcia:

O reino é dom, mas é um dom pessoal, que suscita uma resposta do ser humano. A atuação da Boa-Nova, que é o Reino de Deus, e à vivência da conversão, entendida como arrependimento do mal realizado e como orientação da vida em conformidade com a vontade de Deus. Assim, a resposta que o dom do Reino suscita consiste, com a conversão, na abertura e na entrega da pessoa, vividas na fé e na confiança [...] Esta fé-confiança é indispensável para todo aquele que aceita o dom do Reino de Deus. ${ }^{18}$

A salvação como libertação é uma consequência da salvação como gratuidade. No final das contas, os conceitos salvíficos se complementam. Um não anula o outro. Observando-os, entretanto, separadamente, é possível

\footnotetext{
${ }^{16}$ Para uma leitura mais específica da relação entre os conceitos de salvação cristã e a proposta apaqueana, convém consultar: LIRA JUNIOR, J. N., Matar o criminoso e salvar o homem: análise da proposta salvífica da Associação de Proteção e Assistência aos Condenados - APAC.

${ }^{17}$ MOLTMANN, J., Trindade e Reino de Deus, p. 129.

${ }^{18}$ RUBIO, A. G., O Encontro com Jesus Cristo Vivo, p. 47.
} 
notar suas peculiaridades. A libertação, com suas implicações, é uma noção salvífica que partiu das Escrituras, atravessou a história e chegou à atualidade com novas expressões. No Antigo Testamento o êxodo do Egito é a libertação do povo de Deus. No Novo Testamento a promessa de libertação é cumprida no nascimento, morte e ressurreição do Messias. Na história da igreja cristã, desde o período dos pais da Igreja, essa libertação ganha enfoques como o resgate - outra noção salvífica muito similar à libertação, porém com suas peculiaridades e implicações, especialmente na teologia de Orígenes, um dos primeiros a tratar do resgate como preço pago ao diabo em troca da libertação das almas cativas. ${ }^{19}$ Para Tomás de Aquino o preço pago pelo resgate das almas, na Paixão, se tornou conveniente, satisfez, tanto a justiça como a misericórdia divina. ${ }^{20}$ Daí outro conceito salvífico, a saber a satisfação vicária. Ou seja, não há salvação desassociada de uma penalidade, pelo contrário, só há salvação porque Jesus Cristo sofreu a pena, pelos pecados do ser humano ${ }^{21}$. As implicações dessa satisfação são várias: justiça, misericórdia, penalidade, vingança sanguinária, etc. $\mathrm{Na}$ atualidade, novos enfoques como a teologia da libertação e a libertação integral, também com as suas implicações, ganharam destaque. Não é possível, aqui, entrar nos pormenores dessas expressões. Mas, é possível entender, mesmo que de maneira sucinta, como essas noções de salvação cristã brevemente lembradas - da gratuidade à satisfação vicária implicaram iniciativas ressocializadoras, como a apaqueana.

Considerando o aspecto confessional da APAC é possível notar a estreita relação entre o seu pensar teológico e o seu método. "Matar o criminoso e

\footnotetext{
${ }^{19}$ ORÍGENES apud SESBOÜÉ, B., Na esteira de Calcedônia, p. 390.

${ }^{20}$ Para um melhor entendimento do pensamento de Tomás de Aquino, quanto à satisfação vicária, convém consultar SESBOÜÉ, B., Na esteira de Calcedônia, p. 415-418.

${ }^{21}$ É importante ressaltar que a noção de salvação cristã como satisfação vicária, no ocidente, é influenciada por Santo Anselmo e São Tomás de Aquino, muito embora a soteriologia destes doutores não se limite a esta noção. Apesar dessa importante influência, há alternativas que ampliam esta noção e também as que a interpelam. Joseph Moingt, por exemplo, observa a morte de Cristo pelo sentido que, segundo ele, o próprio Jesus lhe dá e não pelos sentidos de expressões como o da expiação, pois Jesus mesmo "deu à sua morte um sentido salvífico, mas não expiatório" (MOINGT, J., O Homem que Vinha de Deus, p. 364). Com isso, o referido teólogo não está querendo dizer que não haja interpretação sacrificial da morte de Cristo, mas procura julgar e medir o alcance dessa interpretação. Na exegese moingtiana do termo resgate - utilizado como base da interpretação expiatória - não há espaço para a expiação, mas há, sim, uma hermenêutica do serviço. Para outras contribuições (de ampliação ou interpelação) desta noção de salvação cristã, convém consultar: LIRA JUNIOR, J. N., Matar o criminoso e salvar o homem: análise da proposta salvífica da Associação de Proteção e Assistência aos Condenados - APAC, p. 63-104.
} 
salvar o homem" é controverso para os que não estão familiarizados com o sistema. Para os que estão envolvidos na dinâmica apaqueana, o slogan é perfeitamente compreensível e cabível num contexto, ao mesmo tempo, religioso e hostil. Religioso pelo fato de se tratar de uma instituição penal alternativa, confessionalmente cristã. Hostil pelo fato de estar inserida num universo prisional brasileiro em crise, acolhendo pessoas que inicialmente não entendem outra linguagem senão a do crime. "Matar", embora soe incoerente e politicamente incorreto do ponto de vista dos direitos humanos, no contexto apaqueano do slogan é sinônimo de eliminar, deixar para trás, converter como no contexto paulino do velho homem que dá lugar ao novo (Ef 4,22-24).

O objetivo da APAC, portanto, é a salvação do apenado. Uma salvação socioantropologicamente legítima na medida em que visa à ressocialização dos recuperandos - condenados que cumprem pena na APAC. Uma salvação teologicamente observada na medida em que visa à prática querigmática do Evangelho de Jesus Cristo, de maneira gratuita, para a libertação física e espiritual do condenado que também é minoria marginalizada. As relações com os conceitos salvíficos apresentados não param por aqui. A salvação proposta pelo método apaqueano é também resgatadora quando se dispõe a pagar o preço por um cumprimento de pena humanizado. Uma salvação ao estilo da satisfação vicária, porquanto visa a satisfazer à justiça humana e à divina, quando não menospreza nem a função punitiva da pena de prisão nem o princípio bíblico das consequências do pecado.

Assim, a proposta salvífica da APAC é uma relação dialógica entre a teologia e direito, entre o divino e o humano, entre a sociedade livre e a sociedade cativa, entre a teoria e a prática penais. Tal relação dialógica direciona esta reflexão para o próximo e último ponto.

\section{Os Direitos Humanos na APAC}

Após uma breve observação de dois aspectos importantes da APAC, a saber, o jurídico e o teológico, pretende-se agora verificar se a APAC observa, respeita, pratica, os direitos humanos no âmbito do seu sistema. Antes, é necessário limitar tais direitos observados aqui, ou seja, os que estão explícitos nos artigos $5^{\circ}$ a $11^{\circ}$ da Declaração Universal dos Direitos Humanos:

Artigo $5^{\circ}$ : Ninguém será submetido à tortura, nem a tratamento ou castigo cruel, desumano ou degradante. Artigo $6^{\circ}$ : Todo ser humano tem o direito 
de ser, em todos os lugares, reconhecido como pessoa perante a lei. Artigo $7^{\circ}$ : Todos são iguais perante a lei e têm direito, sem qualquer distinção, a igual proteção da lei. Todos têm direito a igual proteção contra qualquer discriminação que viole a presente Declaração e contra qualquer incitamento a tal discriminação. Artigo $8^{\circ}$ : Todo ser humano tem direito a receber dos tribunais nacionais competentes remédio efetivo para os atos que violem os direitos fundamentais que lhe sejam reconhecidos pela constituição ou pela lei. Artigo $9^{\circ}$ : Ninguém será arbitrariamente preso, detido ou exilado. Artigo $10^{\circ}$ : Todo ser humano tem direito, em plena igualdade, a uma justa e pública audiência por parte de um tribunal independente e imparcial, para decidir seus direitos e deveres ou fundamento de qualquer acusação criminal contra ele. Artigo $11^{\circ}: 1$. Todo ser humano acusado de um ato delituoso tem o direito de ser presumido inocente até que a sua culpabilidade tenha sido provada de acordo com a lei, em julgamento público no qual lhe tenham sido asseguradas todas as garantias necessárias à sua defesa. 2. Ninguém poderá ser culpado por qualquer ação ou omissão que, no momento, não constituíam delito perante o direito nacional ou internacional. Também não será imposta pena mais forte de que aquela que, no momento da prática, era aplicável ao ato delituoso. ${ }^{22}$

Estão explícitos nestes artigos a proteção da dignidade humana, a igualdade, o direito à defesa, os limites da pena. Tais direitos são contemplados na LEP e no Código Penal de 1984, porém, na prática, nem sempre são oferecidos pelo sistema penal brasileiro. Pelo contrário. Há muita desumanidade. Ao tratar da aplicação da pena observando-se tão somente a função punitiva, no ponto anterior, lembrou-se da Lei de Talião. Porém, o que se pratica nos presídios brasileiros é pior que o Talião. O "Olho por olho, dente por dente" seria menos cruel do que certas torturas praticadas em muitos estabelecimentos penais. Mais cruel ainda é o que está, via de regra, no subconsciente do senso comum: "Pena de morte é pouco. Comida azeda é pouco. Celas superlotadas é pouco. Qualquer espécie de tortura física e psicológica é pouco. Se cada um dos condenados enlouquecesse e passasse o resto das suas vidas miseráveis nas mais degradantes situações sub-humanas, ainda seria muito pouco". Talvez por opiniões assim, falar sobre direitos humanos ainda seja uma tarefa mal compreendida no Brasil, pois estaria, na concepção da maioria do senso comum, se falando de "benefícios", "vantagens", para quem não merece. Um equívoco na concepção da DUDH e da Constituição Brasileira, na medida em que todos são iguais perante a lei.

${ }^{22}$ DECLARAÇÃO Universal dos Direitos Humanos, Artigos $5^{\circ}$ ao $11^{\circ}$. 
Tais desumanidade e desigualdade tem levado a sociedade brasileira a desprezar o sistema carcerário. Até agosto de 2018, era difícil precisar o número da população carcerária brasileira, até que a então presidente do Conselho Nacional da Justiça (CNJ) e do Supremo Tribunal Federal (STF), ministra Cármen Lúcia, apresentou a nova versão do Banco Nacional de Monitoramento de Presos (BNMP 2.0). A partir de então, qualquer pessoa pode ter acesso ao número atualizado de presos no Brasil. Na ocasião, a conselheira do CNJ, Maria Tereza Uille, enfatizou: "Não saber quem é e onde está o preso é ferir a dignidade humana. Estamos vivendo um marco histórico e o CNJ tem um papel fundamental na gestão desses dados". ${ }^{23}$ Contabilizar, portanto, a população cativa é fundamental na tomada de medidas que facilitem o controle e aumentem a humanização. Quantos desses presos, por exemplo, tem assistência jurídica na prática? É fato que há o direito a um defensor público, garantido na Lei 7.210, de Execução Penal, de 1984, no Art. 15. ${ }^{24}$ O Art. 16 reza: “As Unidades da Federação deverão ter serviços de assistência jurídica, integral e gratuita, pela Defensoria Pública, dentro e fora dos estabelecimentos penais". ${ }^{25}$ Pelo elemento $5^{\circ}$, "Assistência Jurídica", os recuperandos apaqueanos, e seus familiares, tem todas as informações necessárias ao justo cumprimento da sua pena. Assim, procurando unir teoria e prática, no que diz respeito à pena humanizada, é que a APAC, como instituição confessional e penal, atua nesse cenário. Teologia e direitos humanos aqui se encontram no objetivo de "matar o criminoso e salvar o homem". No cristianismo, como no direito penal, não há salvação humana sem humanização. Por isso, Deus se fez Homem. Um olhar mais atento perceberá que a preocupação da APAC, em relação aos direitos humanos, ultrapassa os seus limites físicos-logísticos. ${ }^{26}$ Além do zelo com a dignidade, bem como com a igualdade, o direito à defesa, os limites da pena impostos aos presos - conhecidos no sistema apaqueano como "recuperandos" - há uma preocupação com os seus familiares (observados no $8^{\circ}$ elemento apaqueano), bem como com a sociedade que,

${ }^{23}$ ANDRADE, P., Cármen Lúcia apresenta ao CNJ o novo banco nacional de presos.

24 "A assistência jurídica é destinada aos presos e aos internados sem recursos financeiros para constituir advogado". BRASIL, Lei no 7.210, de 11 de julho de 1984.

${ }^{25}$ BRASIL, Lei no 7.210, de 11 de julho de 1984.

${ }^{26}$ A higiene, o respeito, o vocabulário, a relação dialógica, a recepção, todos esses aspectos são notados por todos os que visitam as unidades apaqueanas. As famílias dos presos, especialmente as crianças, notam o trato humanizado, sem perder a característica penal, oferecido aos seus entes queridos detidos na APAC. 
conforme o $1^{\circ}$ elemento do método, acolhe o detento durante e após o cumprimento da pena. ${ }^{27}$

\section{Conclusão}

Longe do fim, o embate na controvérsia carcerária brasileira ainda pede a atenção dos diversos vieses de pesquisa. A contribuição teológica prevista aqui, se deu na medida em que se procurou, nesta breve reflexão, observar em que medida a Associação de Proteção e Assistência ao Condenado exerce a tripla função da pena, oferece salvação cristã e ressocialização, bem como obedece aos direitos humanos dos condenados que cumprem pena em suas dependências. Dentre outras constatações, destacam-se a Teologia, o Direito Penal e os Direitos Humanos como disciplinas que se relacionam dialogicamente na APAC devido às características confessional e penal desta instituição.

Outra constatação é a de que, na APAC, para além do diálogo está a práxis. Na medida em que o método apaqueano se propõe a "matar o criminoso e salvar o homem", ele se lança em direção ao apenado, numa altitude cristã, jurídica, com alteridade, para lhe oferecer cumprimento de pena humanizado e possibilidade real de ressocialização. Obviamente, esta brevíssima reflexão requer mais dedicação, mais respostas a problemas como: qual seria a posição da Agenda Nacional pelo Desencarceramento em relação à APAC? Quais hipóteses teriam o olhar teológico salvífico, com o auxílio das disciplinas afins, diante de questões como esta? Diante do aumento da população carcerária e seus desafios inerentes, o melhor caminho a ser traçado pelo sistema penal brasileiro seria, mesmo, o desencarceramento, ou um encarceramento mais humano? Tais pistas deixam abertas as portas para que outros olhares contribuam com esse hodierno tema.

\section{Referências bibliográficas}

APAC Tem Reincidência Quatro Vezes Menor que Regime Comum no RN. Brasília, Conselho Nacional de Justiça - CNJ, 2017. Disponível em:

\footnotetext{
${ }^{27}$ Pela APAC, são chamadas à reflexão e prática ressocializadoras tanto a sociedade cativa sob sua responsabilidade, como a sociedade livre no contexto político, econômico, religioso, no qual está inserido o Centro de Reintegração Social. Em outras palavras, uma unidade apaqueana só consegue funcionar bem com o apoio da sociedade local e regional.
} 
$<$ https://www.cnj.jus.br/apac-tem-reincidencia-quatro-vezes-menor-queregime-comum-no-rn/>. Acesso em: 01 ago. 2020.

BANCO Nacional de Monitoramento de Presos (BNMP 2.0). Disponível em: $<$ https://www.cnj.jus.br/sistema-carcerario/cadastro-nacional-de-presosbnmp-2-0/>. Acesso em: 07 nov. 2020.

BITENCOURT, C. R. Falência da pena de prisão: causas e alternativas. São Paulo: Revista dos Tribunais, 1993.

BRASIL. Lei n ${ }^{\circ} 7.209$, de 11 de julho de 1984. Altera o Decreto-lei ${ }^{\circ} 2.848$, Código Penal, de 7 de desezmbro 1940. Disponível em: $<$ http://www.in.gov. br/mp_leis/leis_texto.asp?Id=LEI\%209887>. Acesso em: 20 mar. 2019.

BRASIL. Lei $n^{\circ} 7.210$, de 11 de julho de 1984. Institui a Lei de Execução Penal. Disponível em: <http://www.planalto.gov.br/ccivil_03/LEIS/L7210. htm>. Acesso em: 28 de jan. 2019.

DECLARAÇÃO Universal dos Direitos Humanos. Disponível em: <https:// www.unicef.org/brazil/declaracao-universal-dos-direitos-humanos $>$. Acesso em: 24 de jan. 2019.

GRECO, R. Sistema Prisional: colapso atual e soluções alternativas. Niterói -RJ: Editora Impetus, 2016.

IPEA - Instituto de Pesquisa Econômica Aplicada. Reincidência Criminal no Brasil: Relatório de Pesquisa, 2015. Disponível em: <http://www.ipea.gov.br/ agencia/images/stories/PDFs/relatoriopesquisa/150611_relatorio_reinci dencia_criminal.pdf $>$. Acesso em: 10 ago. 2020.

IPEA - Instituto de Pesquisa Econômica Aplicada. Reincidência Criminal no Brasil. Rio de Janeiro: 2015. 156p. Relatório Técnico.

LIRA JÚNIOR, J. N. Matar o criminoso e salvar o homem: análise da proposta salvífica da Associação de Proteção e Assistência aos Condenados APAC. Rio de Janeiro, 2017. 153p. Tese. Faculdade de Teologia, Pontifícia Universidade Católica do Rio de Janeiro.

LIRA JÚNIOR, J. N. Matar o criminoso e salvar o homem: o papel da religião na recuperação do penitenciário: um estudo de caso da APAC - Associação de Proteção e Assistência aos Condenados em Itaúna - MG. São Paulo, 2009, 110p. Dissertação.

MARTINS, J. D. A condição do Encarcerado no Sistema Prisional: biopolítica e desenvolvimento como liberdade. Rio de Janeiro: Lumen Juris, 2017.

MOINGT, J. O Homem que Vinha de Deus. São Paulo: Loyola, 2008. 
MOLTMANN, J. Trindade e Reino de Deus: Uma contribuição para a teologia. Petrópolis: Vozes, 2011.

MOTTA, M. B. Crítica da Razão Punitiva: Nascimento da Prisão no Brasil. Rio de Janeiro: Forense Universitária, 2011.

NEDER, G. Sentimentos e Ideias Jurídicas no Brasil: Pena de Morte e Degredo em Dois Tempos. In: MAIA, N. M; NETO, F. S.; COSTA, M.; BRETAS, M. L. (Org.). História das Prisões no Brasil. Rio de Janeiro: Rocco, 2009. p. 79-134. v. 1.

OTTOBONI, M. O testemunho de minha vida e a vida de meus testemunhos. São Paulo: Paulinas, 2012.

OTTOBONI, M. Vamos Matar o Criminoso? Método APAC. São Paulo: Paulinas, 2001.

PARENTE, F. Ressocialização: você também é responsável. Rio de Janeiro: Lumen Juris, 2018.

PINHO, R. R. História do Direito Penal Brasileiro - Período Colonial. São Paulo: Bushatsky / EDUSP, 1973.

RUBIO, A. G. O Encontro com Jesus Cristo Vivo: um ensaio de cristologia para nossos dias. São Paulo: Paulinas, 2007.

SESBOÜÉ, B. Na esteira de Calcedônia: cristologia e soteriologia a partir do século VI. In: SESBOÜÉ, B. (Org.). História dos Dogmas. O Deus da Salvação (Séculos I a VIII). São Paulo: Loyola, 2002. p. 355-424. t.1.

José do Nascimento Lira Júnior

Doutor em Teologia pela Pontifícia Universidade Católica do Rio de Janeiro Docente na Escola Superior de Ensino - Fabra Serra / ES - Brasil E-mail: prlirajunior@yahoo.com.br

Recebido em: 28/08/2020

Aprovado em: 23/09/2021 